\title{
АКАДЕМИЧЕСКОЕ И ОБРАЗОВАТЕЛЬНОЕ ПРОИЗВОДСТВО СТУДЕНТА МАГИСТРАТУРЫ В ЕРТ IFAP MACAPÁ, AMAPÁ, AMAZÔNIA, БРАЗИЛИЯ
}

\section{ОРИГИНАЛЬНАЯ СТАТЬЯ}

VIANA, Valderi Nascimentoํㅜ, FECURY, Amanda Alves², OLIVEIRA, Euzébio de ${ }^{3}$, DENDASCK, Carla Viana ${ }^{4}$, DIAS, Claudio Alberto Gellis de Mattos ${ }^{5}$

VIANA, Valderi Nascimento. Эт аль. Академическое и образовательное производство студента магистратуры в EPT IFAP Macapá, Amapá, Amazônia, Бразилия. Revista Científica Multidisciplinar Núcleo do Conhecimento. Год 06, эд. 06, Vol. 08, стр. 186-200. Июнь 2021 года. ISSN: 2448-0959, Ссылка доступа: https://www.nucleodoconhecimento.com.br/образование-ru/студентамагистратуры, DOI: 10.32749/nucleodoconhecimento.com.br/ru/89151

\section{СВОДКА}

Научное производство в рамках бакалавриата и аспирантуры имеет свое значение для создания нового способа мышления студента. Профессиональная степень магистра профессионального образования в национальной сети (ProfEPT) объединяет дисциплинарный контент, педагогические знания и итоговую академическую продукцию и связывает их с реальными ситуациями

\footnotetext{
${ }^{1}$ Физический педагог, специалист по физиологии упражнений и спортивному питанию (FAMA), студент высшей программы профессионального и технологического образования (PROFEPT IFAP).

${ }^{2}$ Биомедицинская, phD в тропических заболеваниях, профессор и исследователь медицинского курса кампуса Масара́, Федеральный университет Amapá (UNIFAP).

${ }^{3}$ Биолог, кандидат тропических болезней, профессор и исследователь курса физкультуры Федерального университета Pará (UFPA).

${ }^{4}$ Богослов, кандидат медицинских наук в области клинического психоанализа. Он работает в течение 15 лет с научной методологией (метод исследования) в научно-производственном руководстве магистра и докторантуры. Специалист по исследованиям рынка и исследованиям, ориентированным на здоровье. Аспирант в области коммуникации и семиотики (PUC SP).

${ }^{5}$ Биолог, кандидат теоретических и летных исследований, профессор и исследователь курса химической степени Института базового, технического и технологического образования Amapá (IFAP) и Высшей программы профессионального и технологического образования (PROFEPT IFAP).

RC: 89151

Ссылка доступа: https://www.nucleodoconhecimento.com.br/образование-ru/студента- 
образовательной практики, а окончательная работа может быть представлена различными способами (статьи, книги, образовательные продукты). Академическое производство, как советника, так и руководства, в дополнение к важности, связанной с научным распространением, имеет вес в оценке программы, а также в ее обслуживании. Цель этой работы состоит в том, чтобы количественно показать академическое и образовательное производство студента магистратуры в области профессионального и технологического образования (ЕРТ) из Института образования, науки и техники (IFAP) Macapá, Amapá, Amazônia, Бразилии. Во время магистратуры в процессе обучения оказалось необходимым научное производство в различных формах. Объединив теорию с практикой письма, облегчила выработку диссертации, которая должна быть представлена в конце курса. В процессе организации планирование идей привело к новой мысли, структурированной в соответствии со стандартами академии, но это не ограничивается этим пространством и нормами. Продукция в ходе магистратуры стремится внести как количественный, так и качественный вклад в научное производство северного региона, положительно влияя на него и магистерская программа. Помимо важного вклада в научное создание и распространение, постановки, как правило, положительно влияют на оценку и содержание программы PROFEPT-IFAP, проведенной CAPES.

Ключевые слова: ЕPT, Распространение, Научное производство, PRORFEPT.

\section{ЗНАКОМСТВО}

Объединяя теоретические и методологические инструменты, возможности реализации новых проектов, студент перестает быть просто ретранслятором и начинает производить знания, внося свой вклад в конкретную тему или область. Через строительство собственной мысли, они производят новые отношения и поведение, то есть, он подвергает правдоподобной и структурированной идеи, представляя значение суждений и критический смысл с действительным и логическим аргументации (Маiа, 2008). 
Профрессиональная степень магистра профессионального образования в национальной сети (ProfEPT) становится возможностью для конкретного обучения по профрессиональному и технологическому образованию как для сотрудников фредеральных институтов, так и для внешнего населения, имеющих производство знаний через образовательные продукты и научные достижения, которые относятся к миру труда. В этом условии целью является объединение дисциплинарного содержания и педагогических знаний, итоговая академическая постановка должна быть увязана с реальными ситуациями образовательной практики, а окончательная работа может быть представлена различными способами (Machado e Urbanetz, 2019; Urbanetz et al., 2020).

Для производства и публикации научных знаний руководство играет основополагающую роль. Консультант, имеющие большой опыт в издательской деятельности, становится наставником для своего наставничества, положительно влияя на производительность, отвечая за обучение прогрессу и успеху в будущем студента. То есть весь опыт, полученный в ходе учебного процесса, положительно влияет на академическую жизнь студента, навыки и навыки для публикации выучены во время обучения (Falaster et al., 2017).

В соответствии с оценочной формой для академических и профессиональных программ (Район 46: Преподавание) Координации по совершенствованию персонала высшего образования (CAPES):

[...] соответствующие минимальные производственные мощности PD будут оценены, и может включать студентов и выпускников. Кроме того, будет проведена оценка присоединения и согласования производства, указанного PPG DP (четыре производства) с его концентрационой площадью и научноисследовательскими линиями, что отражает согласованность производства с целями и самобытностью Программы. [...] Для этого PPG будет указывать до пяти библиографических производств и до пяти РТТ опубликованы в четырехлетний период с участием студентов и выпускников. [...] актуальность указанного производства в связи с воздействием и новаторским характером 
интеллектуального производства, местного, регионального, национального или международного охвата и удовлетворение социальных потребностей. (Capes, 2020).

Академическая продукция, как советника, так и наставника, в дополнение к важности, связанной с научным распространением, имеет вес в оценке программы выпускников stricto sensu, а также в ее обслуживании.

\section{ЦЕЛЬ}

Количественно продемонстрировать академическое и образовательное производство студента магистратуры в области профессионального и технологического образования (ЕРТ) из Института образования, науки и техники (IFAP) Macapá, Amapá, Amazônia, Бразилия.

\section{МЕТОДОЛОГИИ}

В этой статье раскрывается интеллектуальное производство, разработанное в ходе ProfEPT - IFAP. Эти постановки, которые можно классифицировать как библиографическое производство (статья в периодическом издании, книга) и техническое производство (приложение - АРР, веб-сайт)

Количественные опросы для получения данных о заявке и веб-сайте использовали период с 12 апреля 2021 года по 14 июня 2021 года. Данные о приложении взяты из Play Console (Playconsole, 2021) и веб-сайта Google Analytics (Googleanalytics, 2021).

Для книг и научных статей дата публикации использовалась до 14 июня 2021 года. Данные о них были взяты из онлайн-данных (книги и статьи, опубликованные в Revista Multidisciplinar Núcleo do Conhecimento) (Rmnc, 2021), а также путем прямой консультации журнала (статья опубликована в журнале Research, Society and Development journal) (Rsd, 2021). 


\section{РЕЗУЛЬТАТЫ}

\section{ЗАЯВKA EFE (EDUFISEPT)}

На рисунке 1 показан процент установок приложений EFE по источнику информационного трафрика в период с 12 апреля по 14 июня 2021 года. Данные показывают, что 21,67\% (13 пользователей) прибыли в приложение через поиск в магазине Google Play и 78,30\% (47 пользователей) по сторонняя ссылка.

Рисунок 1 - Показывает процент установок приложения EFE по источнику информационного трафика в период с 12 апреля по 14 июня 2021 года.

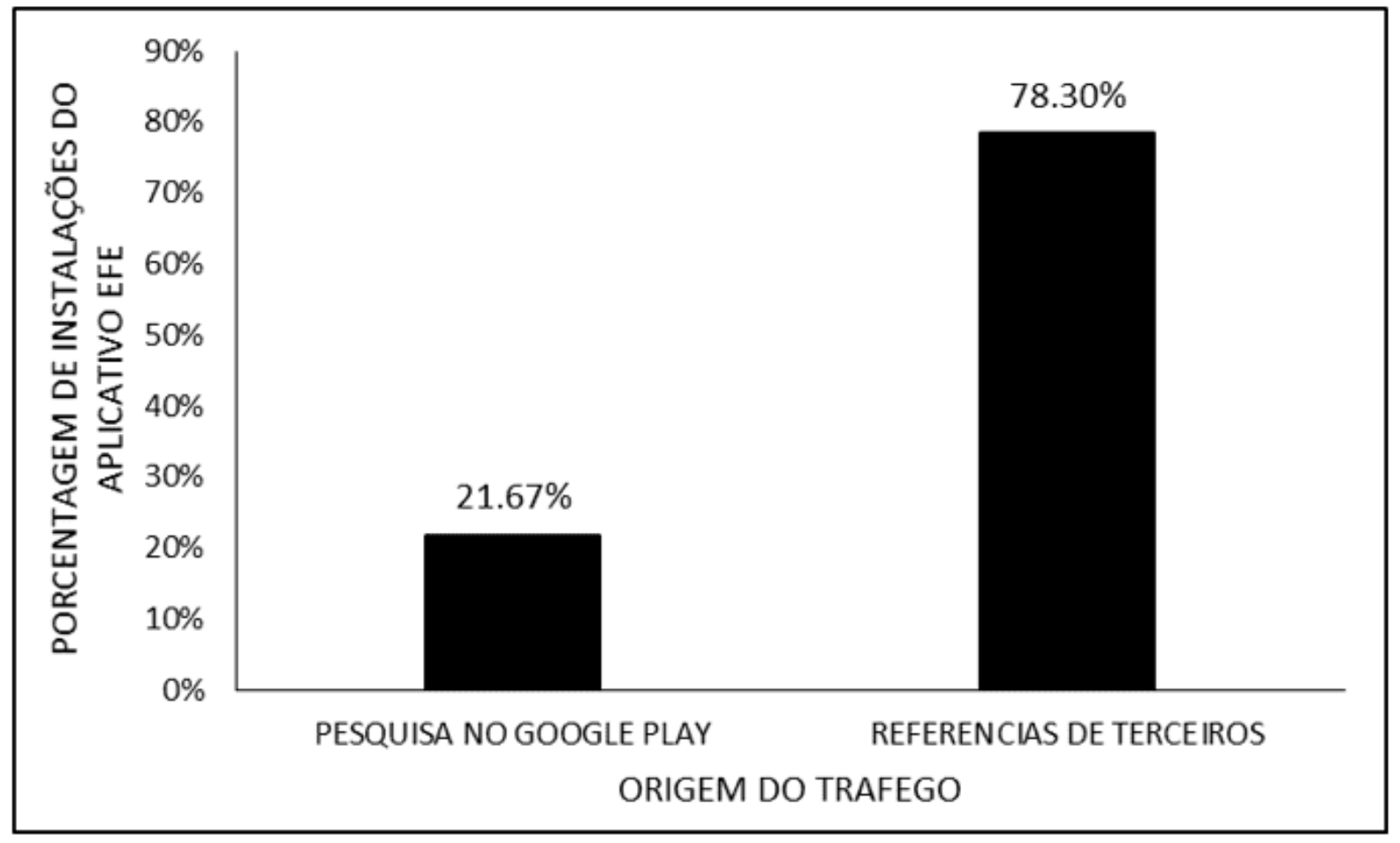

Источник: Адаптировано из Playconsole (2021)

Что касается анализа доли установок приложения EFE в стране пользователя, то в период с 12 апреля по 14 июня 2021 года было рекордное количество загрузок в двух странах: 98,33\% (59 downloads) из Бразилии и 1,67\% из Португалии (01download) (рисунок 2). 
Рисунок 2 - Показывает процент установок приложений EFE по странепользователю в период с 12 апреля по 14 июня 2021 года.

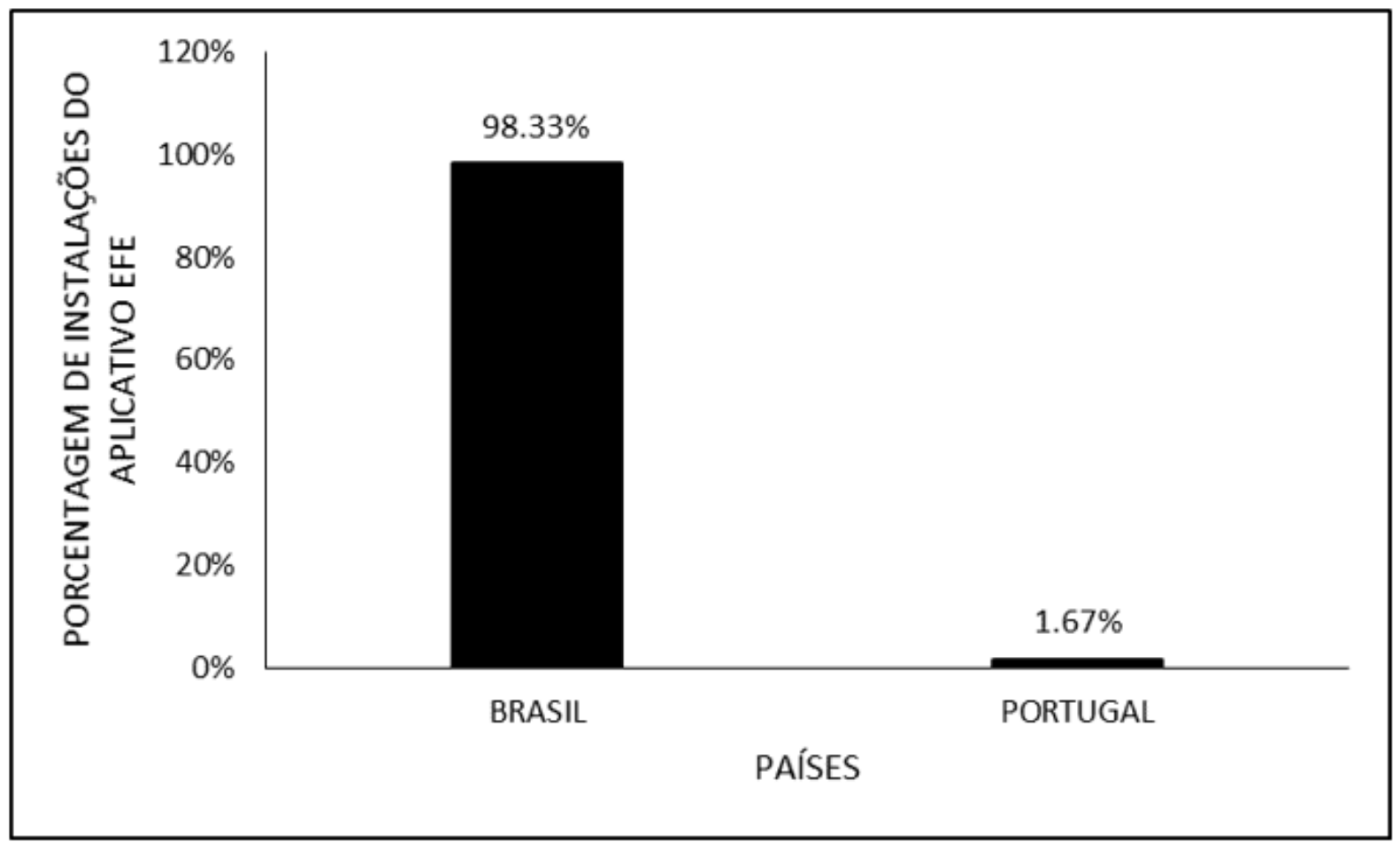

Источник: Адаптировано из Playconsole (2021)

Процент еfе установки приложений по посещению и установке приложений, в период с 12 апреля по 14 июня 2021 года, можно увидеть на рисунке 3.

Из 100\% посетителей страницы в магазине (82 человека) 73,17\% (60 человек) скачали приложение на свое мобильное устройство (рисунок 3). 
Рисунок 3 - Показывает процент EFE приложение устанавливает по посещению приложения и установки в период с 12 апреля по 14 июня 2021 года.

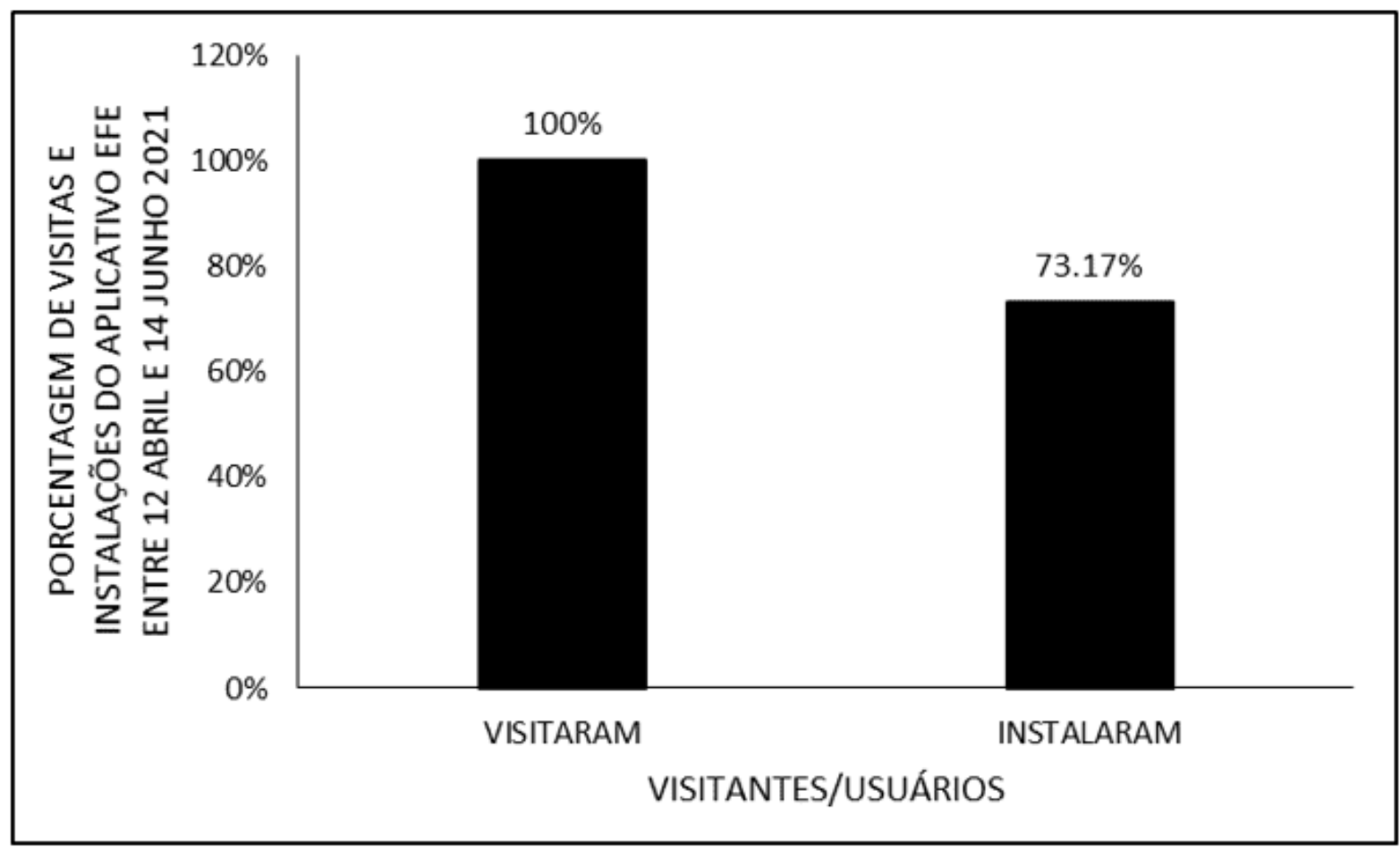

Источник: Адаптировано из Playconsole (2021)

На рисунке 4 показан процент установок приложений EFE по типам пользователей в период с 12 апреля по 14 июня 2021 года. Из общего числа (60 пользователей) 93,33\% (56 человек) являются новыми пользователями и 6,67\% (04 человека) являются постоянными пользователями в приложении, то есть получили доступ к АРP несколько раз. 
Рисунок 4 - Показывает процент установок приложений EFE по типам пользователей в период с 12 апреля по 14 июня 2021 года.

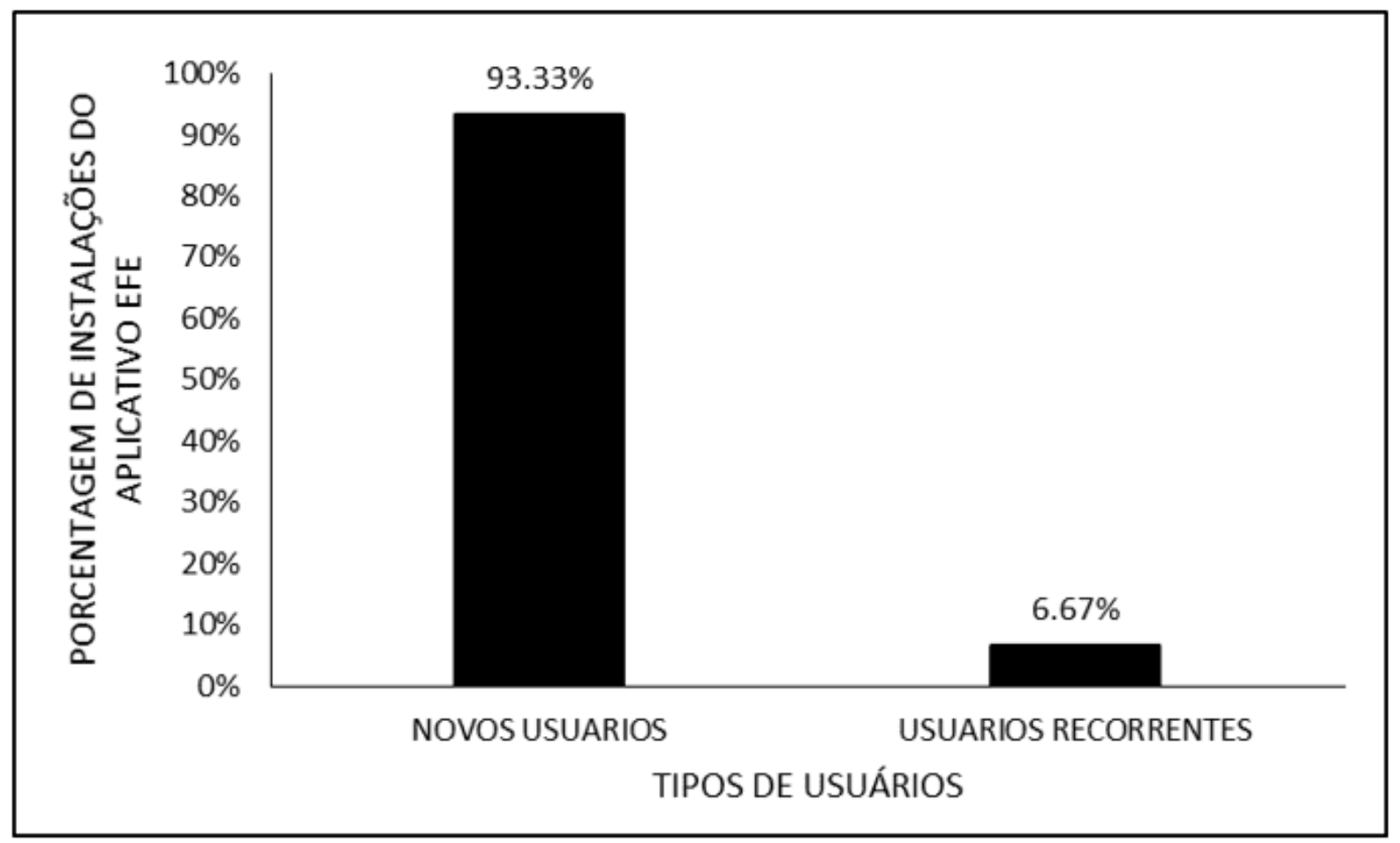

Источник: Адаптировано из Playconsole (2021)

\section{MECTO}

Что касается доли доступа к сайту EduFisEPT по внутренним страницам сайта, то в период с 12 апреля по 14 июня 2021 года страница с самым большим доступом среди 1399 пользователей (100\%) педагогические практики с 30,38\% (425 человек). Далее Страница спорта с 17,23\% (241 человек доступ), Авторы с 13,37\% (187 человек), Сотрудничество с 13,22\% (185 человек), игры и игры с 7,79\% (10 9 человек доступа), Танцы 5,65\% (79 человек), Здоровье с 5,00\% (70 человек), Досуг с 4,43\% (62 человек) и бои с 2,91\% (41 человек) (рисунок 5). 
Рисунок 5 - Показывает процент доступа к сайту EduFisEPT на внутреннюю страницу в период с 12 апреля по 14 июня 2021 года.

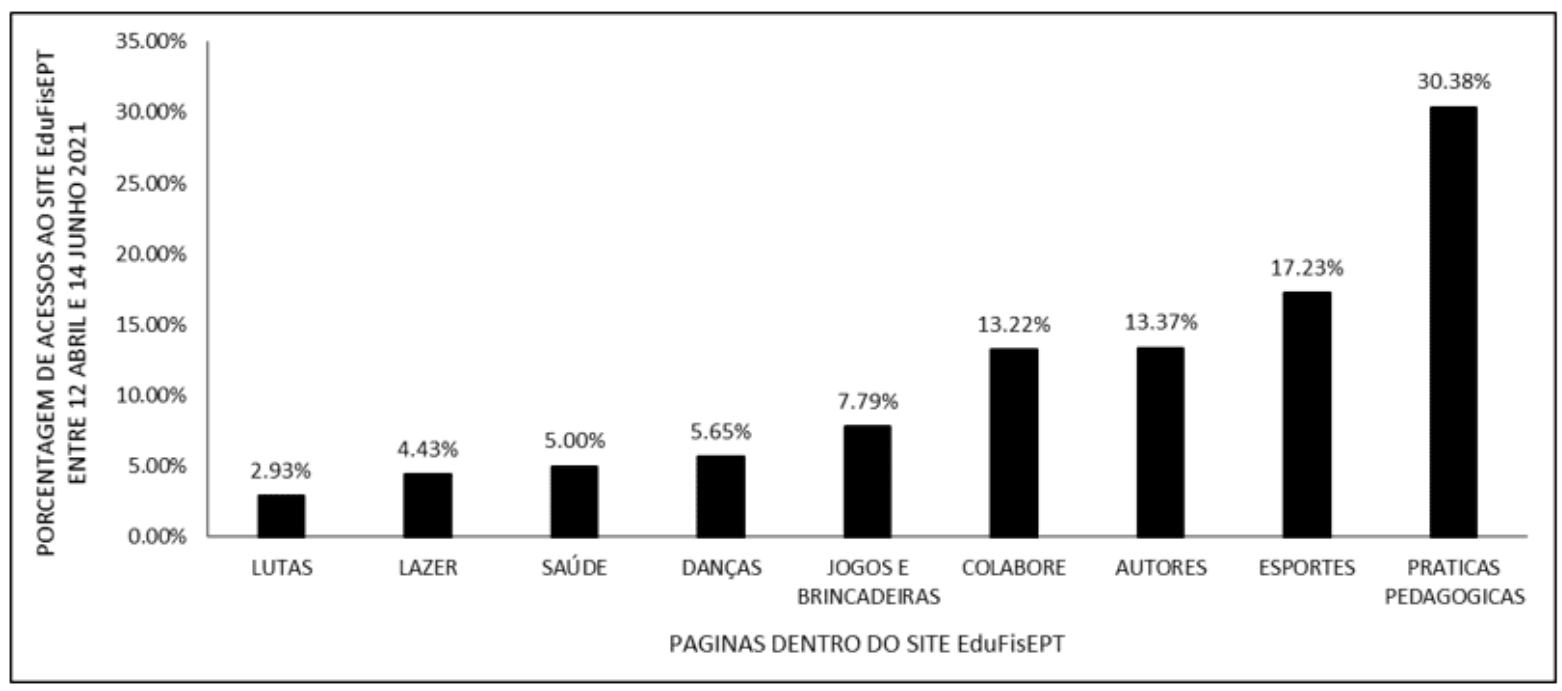

Источник: Адаптировано om GoogleАналитики (2021)

Процент доступа к сайту EduFisEPT по странам в период с 12 апреля по 14 июня, 2021, приносит Бразилии с 93,92\% (1314 человек) доступ, а затем Португалия с 2,64\% (37 человек), Соединенные Штаты с 1,50\% (21 человек), Мозамбик 1,07\% (15 человек), 1,07\%, и Ирландия с 0,86\% (12 человек) (рисунок 6). 
Рисунок 6 - Показывает процент доступа к веб-сайту EduFisEPT по странам в период с 12 апреля по 14 июня 2021 года.

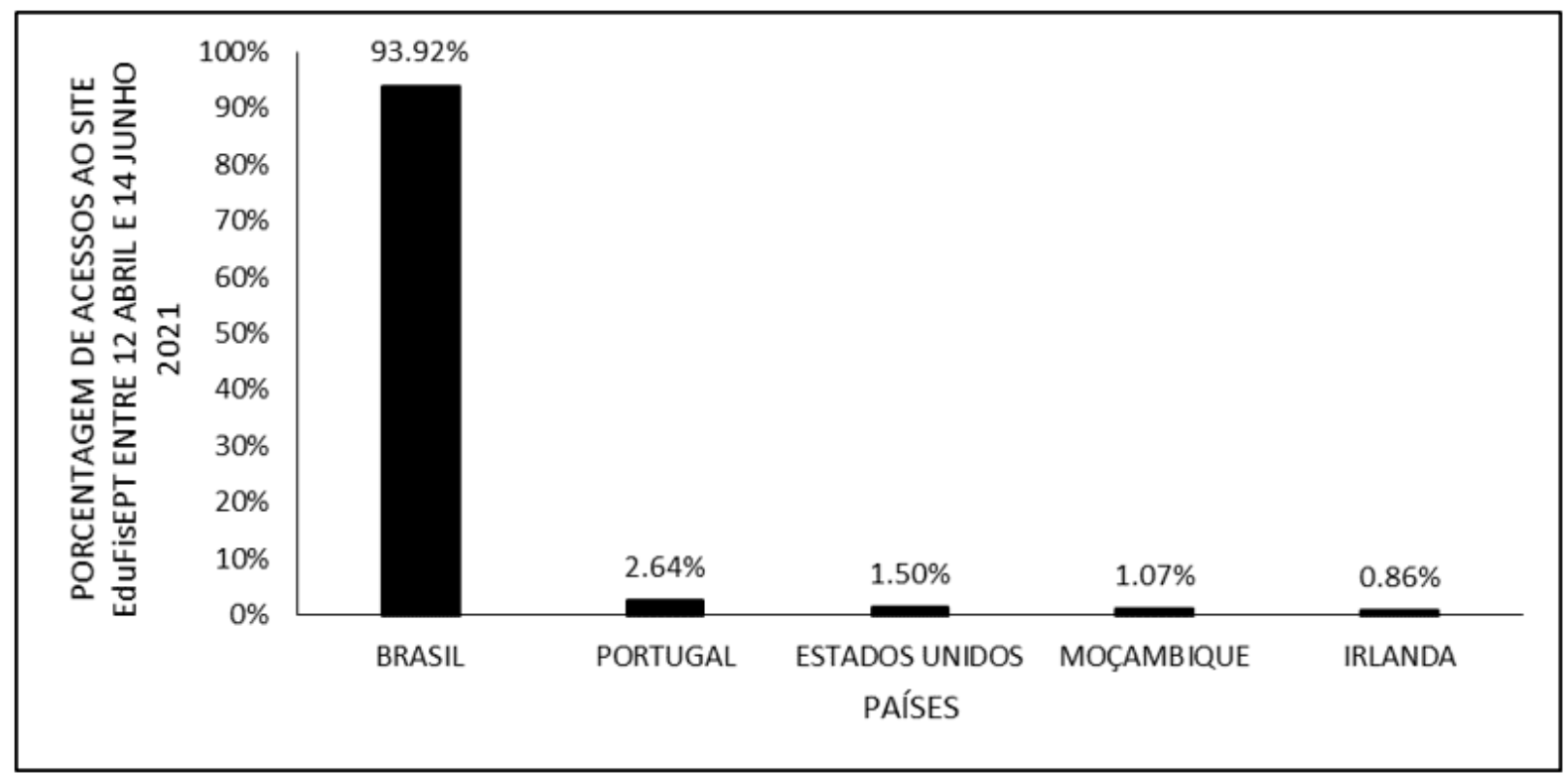

Источник: Адаптировано om GoogleАналитики (2021)

\section{КНИГИ}

На рисунке 7 изображена обложка книги, опубликованной на португальском языке (BR) 30 сентября 2020 года. С момента своего издания книга набрала в общей сложности 715 просмотров. 
Рисунок 7 - Показывает обложку книги, опубликованной на португальском языке (BR) 30 сентября 2020 года.

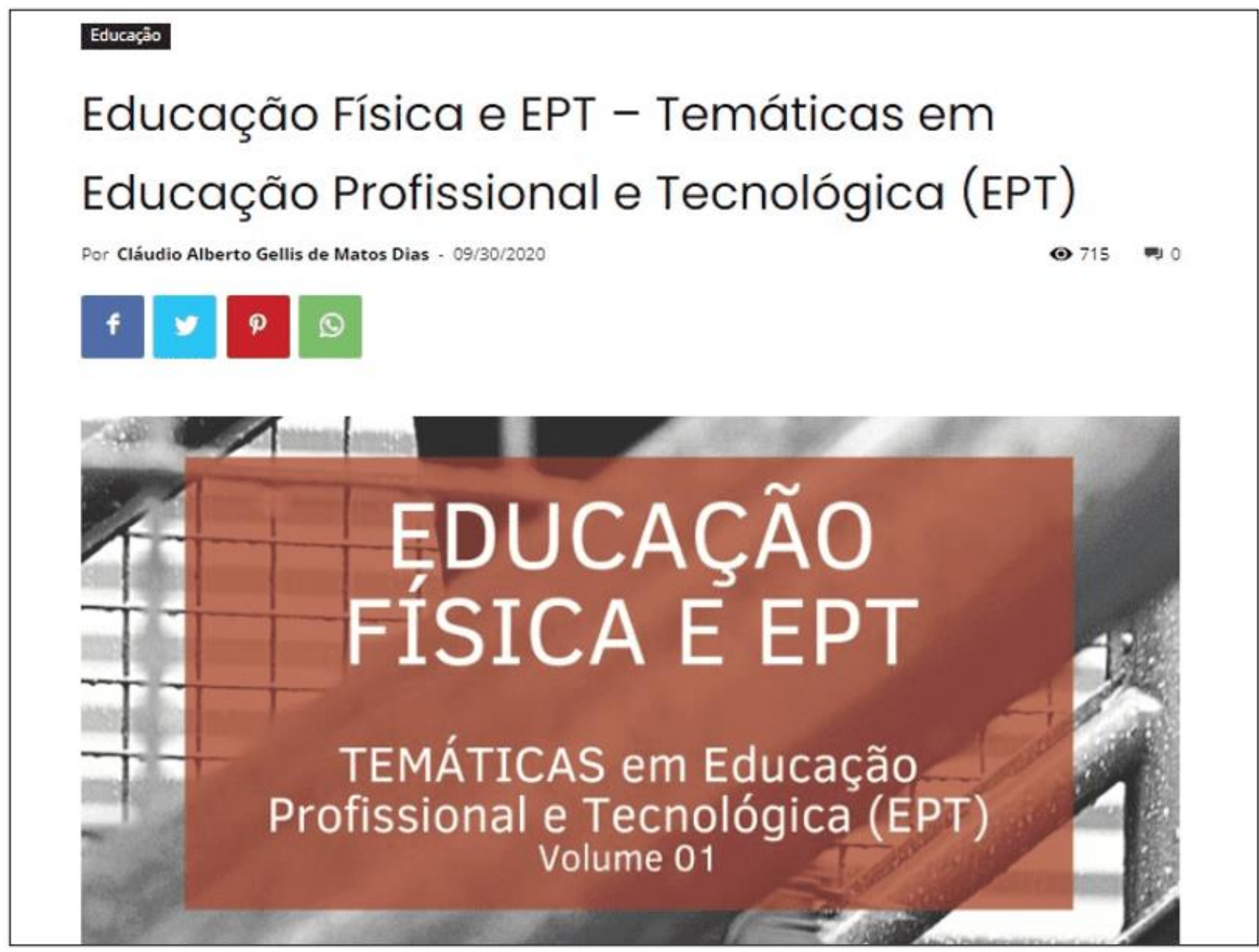

Источник: Адаптировано из Viana и Dias (2020).

Книга, изданная на английском языке (версия книги на португальском языке) от 10 декабря 2020 года, с тех пор набирает 248 просмотров (рисунок 8). 
Рисунок 8 - Показывает обложку книги, опубликованной на английском языке 10 декабря 2020 года.

Education

Physical Education and PTE - Topics in Professional and Technological Education (PTE)

Por Cláudio Alberto Gellis de Matos Dias - 12/10/2020
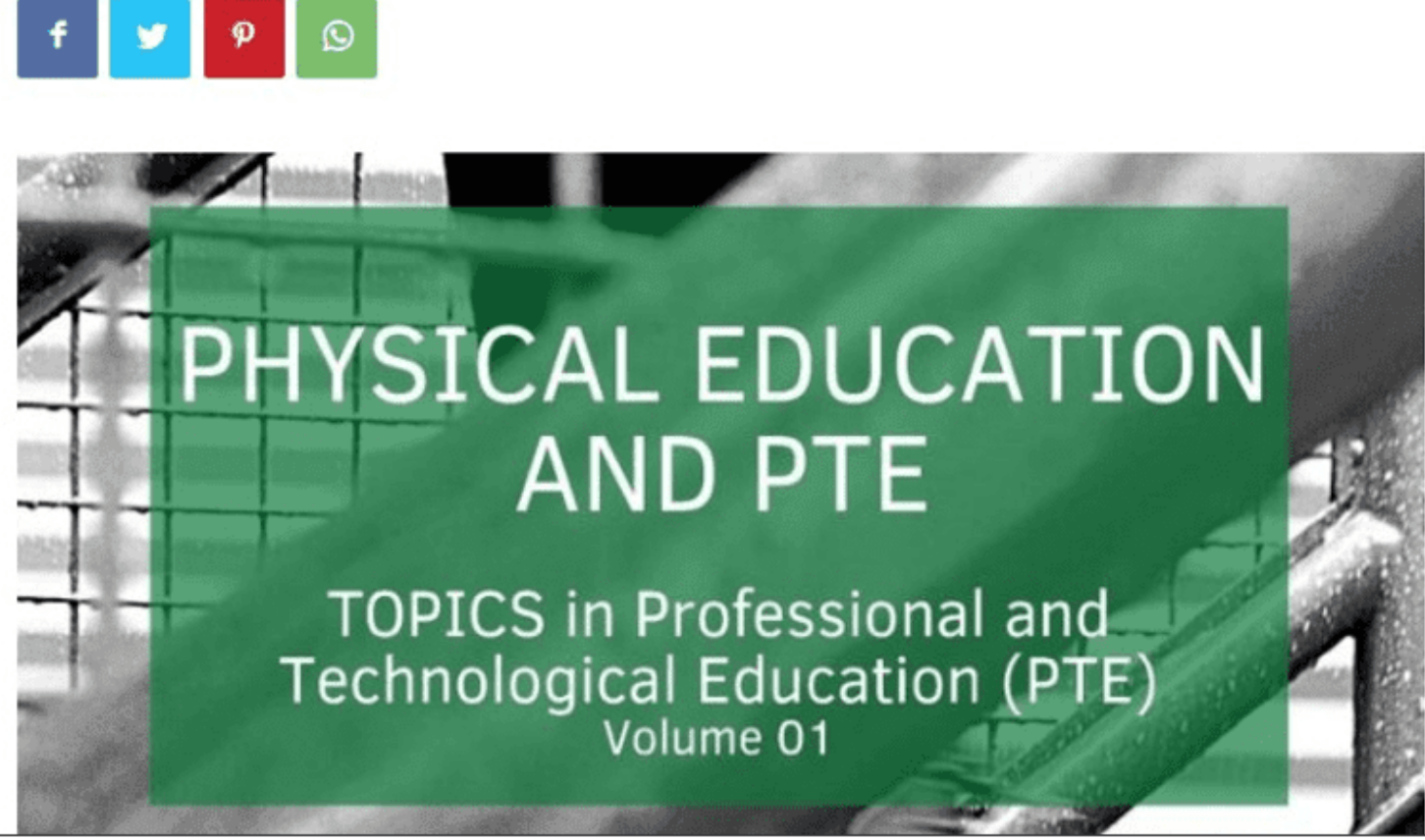

Источник: Адаптировано из Viana и Dias (2020b).

\section{СТАТЬИ, ОПУБЛИКОВАННЫЕ В ИНДЕКСНЫХ ЖУРНАЛАХ}

В статье, опубликованной в журнале Research, Society and Development (Квалис 2013-2016 В2 и Квалис ссылка А3) от 2 июля 2020 года было, по данным редакции, 91 просмотров (рисунок 9). 
На рисунке 9 - показана обложка статьи, опубликованной в журнале Research, Society and Development 2 июля 2020 г.

\begin{tabular}{|} 
Research, Society and Development, v. 9, n. 8, e239985704, 2020 \\
(CC BY 4.0)| ISSN 2525-3409 | DOI: http://dx.doi.org/10.33448/rsd-v9i8.5704 \\
Quadras de esportes em condições de uso adequado no Brasil: \\
influência no ensino-aprendizagem nas aulas de Educação Física (2015) \\
Sports courts in conditions of proper use in Brazil: influence on teaching-learning in \\
Physical Education classes (2015) \\
Canchas deportivas en condiciones de uso adecuado en Brasil: \\
influencia en la enseñanza-aprendizaje en las clases de Educación Física (2015) \\
Recebido: 16/06/2020 | Revisado: 18/06/2020 | Aceito: 22/06/2020 | Publicado: 02/07/2020 \\
ORCD: https://orcid.org/0000-0002-0885-5834 \\
Instituto Federal do Amapá, Brasil \\
E-mail: wallderinascimento@gmail.com
\end{tabular}

На рисунке 10 показана обложка руководства по заявке EFE, опубликованной в Многопрофильном журнале N'слео-до-Конхецименто (ссылка на В3) 14 апреля 2021 года. Публикация на португальском языке имела 244 мнения. 
На рисунке 10 - показана обложка руководства по применению EFE, опубликованного в Revista Multidisciplinar Núcleo do Conhecimento 14 апреля 2021 г.

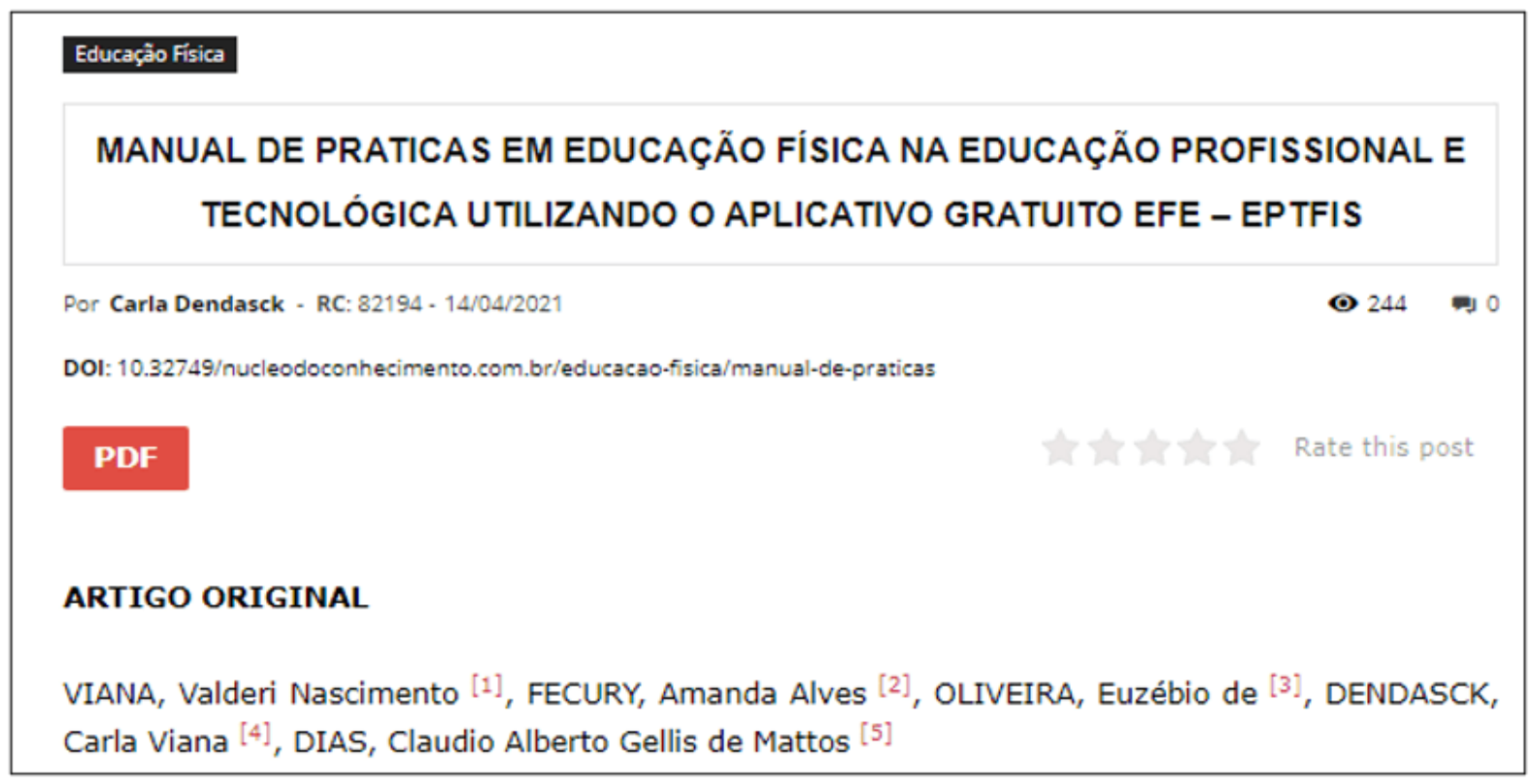

Источник: Адаптировано из Viana et al. (2021)

Руководство было опубликовано еще на шести языках, помимо португальского. В таблице 1 показано количество обращений (и URL) к руководству по приложению EFE, опубликованному в Revista Multidisciplinar Núcleo do Conhecimento до 14 июня 2021 г., с разбивкой по языкам. Всего с момента публикации до 14 июня 2021 года было просмотрено 374 человека. 
В таблице 1 - показано количество обращений (и URL) к руководству по приложению EFE, опубликованному в Revista Multidisciplinar Núcleo do Conhecimento до 14 июня 2021 г., по языкам.

\begin{tabular}{|c|c|c|}
\hline IDIOMA & $\begin{array}{c}\text { NÚMERO } \\
\text { DE } \\
\text { ACESSOS }\end{array}$ & LINK DE ACESSO \\
\hline PORTUGUES & 244 & $\begin{array}{l}\text { https://www.nucleodoconhecimento.com.br/e } \\
\text { ducacao-fisica/manual-de-praticas }\end{array}$ \\
\hline INGLES & 20 & $\begin{array}{l}\text { https://www.nucleodoconhecimento.com.br/e } \\
\text { ducation-physics-en/manual-of-practices }\end{array}$ \\
\hline ESPANHOL & 24 & $\begin{array}{l}\text { https://www.nucleodoconhecimento.com.br/e } \\
\text { ducacion-fisica-es/manual-de-practicas }\end{array}$ \\
\hline FRANCÊS & 23 & $\begin{array}{l}\text { https://www.nucleodoconhecimento.com.br/e } \\
\text { ducation-physics-fr/manuel-de-pratiques }\end{array}$ \\
\hline ITALIANO & 26 & $\begin{array}{l}\text { https://www.nucleodoconhecimento.com.br/e } \\
\text { ducazione-fisica-it/manuale-di-pratiche }\end{array}$ \\
\hline ALEMÃO & 21 & $\begin{array}{l}\text { https://www.nucleodocon hecimento.com.br/b } \\
\text { ildung-physik-de/handbuch-der-praktiken }\end{array}$ \\
\hline RUSSO & 16 & $\begin{array}{l}\text { https://www.nucleodocon hecimento.com.br/o } \\
\text { бразование-физика-ru/пособие-по-практике, }\end{array}$ \\
\hline TOTAL & 374 & \\
\hline
\end{tabular}

Источник: Адаптировано из Viana et al. (2021), Viana et al. (2021b), Viana et al. (2021c), Viana et al. (2021d), Viana et al. (2021e), Viana et al. (2021f), Viana et al. (2021g).

\section{ОБСУЖДЕНИЯ}

В научной среде вся теория и методология направлены на то, чтобы приблизить студента к знаниям, подготовленным наукой. В рамках учебного процесса, контакт с написанием статей, строительство веб-сайтов и приложения, строительство исследований, анализа данных и распространения, оказались очень важными. В каждой постановке проводится исследование реальности, и 
это устанавливает связь с социокультурными ситуациями и контекстами. Контекстуализация знаний является инструментом для значимого обучения. Это оппортунистический, новый опыт или знания отставки, заключается в развитии способности анализировать, гипотезы, критический смысл в рамках текущей структуры, так как взаимодействие с фрактами и явлениями повседневной жизни происходит (Yamaguchi e Furtado, 2019).

Все опубликованные материалы, как в фризическом фрормате, так и в Интернете, служат средством научного распространения. В случае приложения весь охватываемый контент основан на научных знаниях, что обеспечивает легкий и легкий доступ. Учитель получает новые знания и может применять их на практике в школе в режиме реального времени. По словам Rossi (2019)

Остается приблизить науку о статьях и конгрессах к жизни бразильцев, которым так нужно почти все, что касается здоровья, качества жизни, устойчивости, мобильности, использования технологий и гражданства.

Таким образом, как на теоретическом уровне (статьи, книги, веб-сайт), так и применение приложения служат стимулом для научного опыта, заключается в том, чтобы думать о науке, сформулированной с реальностью, доступом и языком, доступным для всех, кто ищет знания. Распространение выходит за рамки системного знания, а также служит для восторга, мотивировать и стимулировать других. (Rossi, 2019).

В области фризического воспитания, видение практики изысканный в технике техники или спортивных результатов по-прежнему очень сильна. Производительность и техника должны рассматриваться учителем, но не рассматриваться в качестве приоритетов и должны быть в рамках стандарта совершенства без уважения индивидуальности студента. В перспективе глобального образования, занятия физкультурой должны работать их объектом исследования в широком измерении, так как студенты вставляются в общество, которое имеет культуру и которое производит значения, а также показывает 
противоречия поведения, отношения, которые должны быть рассмотрены / рассмотрены (Coutinho, 2010; Viana et al., 2020).

Таким образом, с научными постановками, основанными на человеческих и социальных науках, только способствовать области фризического воспитания, превосходя только использование медицинских наук, есть возможность размещения ффизического воспитания на том же уровне актуальности и важности других компонентов школьной программы (Balbino e Urt, 2018). В процессе поиска статьи и книги переводились на другие языки. Такое отношение имеет важное значение для расширения сфреры научных исследований, и производство может быть связано как с национальной, так и с международной литературой, демонстрируя способность к общению, доступу, сотрудничеству и поддержке с тем, что производится миром в рамках физического воспитания (Coutinho, 2010).

Что касается научного производства на Севере, Tо Pereira e Silveira (2019) провели анализ научного производства исследователей из Северного региона на Национальном совещании по исследованию научного образования и сообщили, что Север имеет наименьшее количество исследований, присутствующих на мероприятии. Исследование также показывает, что Amapá не выступала с презентациями и работами в изданиях 2009, 2011, 2013, 2015 и 2017 годов. Согласно исследованию, наибольшее или небольшое количество производств связано с населенным пунктами университетского городка, так как они отвечают за большинство научных мероприятий. Подтверждая вышеупомянутое исследование, Sidone et al. (2016) при анализе производства статей в период 2007-2009 годов в южных и юго-восточных регионах указывает на то, что на них приходится более трех четвертей общего объема производства. Другие регионы, такие как Северо-Восток 15\% и Среднего Запада и Севера вместе не достигли 10\% от общего числа национальных. Помимо концентрации университетов в южных и юго-восточных регионах, еще одним фрактором, влияющим на это производство, является более высокая доступность людских ресурсов. 


\section{Выводы}

Во время магистратуры в процессе обучения оказалось необходимым научное производство в различных формах. Объединив теорию с практикой письма, облегчила выработку диссертации, которая должна быть представлена в конце курса. В процессе организации планирование идей привело к новой мысли, структурированной в соответствии со стандартами академии, но это не ограничивается этим пространством и нормами.

Имея вклад, выходящий за рамки научной письменности, на этом пути обучения был широко, то есть создание приложения, веб-сайтов, книг, статей, методологий педагогической практики. Весь этот опыт положительно скажется на будущем как исследователя и специалиста по физкультуре.

В этом контексте вся продукция в течение магистерской степени также вносит как количественный, так и качественный вклад в научное производство северного региона, положительно влияя на него и магистерская программа. Помимо важного вклада в научное создание и распространение, постановки, как правило, положительно влияют на оценку и содержание программы PROFEPTIFAP, проведенной CAPES.

\section{ссылки}

BALBINO, S. I.; URT, S. D. C. Prática Pedagógica em Educação Física para a Educação Integral em Tempo Integral. Pensar a Prática, v. 21, n. 4, p. 775-785, 2018.

CAPES. Ficha de Avaliação - Programas Acadêmicos e Profissionais Área 46: Ensino. Brasília DF, 2020. Disponível em: < https://www.gov.br/capes/pt-br/centraisde-conteudo/FICHA_ENSINO.pdf >. Acesso em: 14 Jun 2021.

COUTINHO, R. X. A influência da Produção Científica nas Práticas de Professores de Educação Física, Ciências e Matemática em Escolas Públicas 
Municiais de Uruguaiana - RS. 2010. 94p. (Mestrado). Universidade Federal de Santa Maria, Santa Maria RS.

FALASTER, C.; FERREIRA, M. P.; GOUVEA, D. M. R. D. O efeito da publicação científica do orientador na publicação dos seus orientados. Revista de Administração Contemporânea, v. 21, n. 4, p. 458-480, 2017.

GOOGLEANALYTICS. Google Analytics Aplaticativo Oficial EFE - Pagina Inicial. 2021. Disponível em: < https://analytics.google.com/analytics/web/?authuser=1\#/p265457828/reports/default home >. Acesso em: 14 Jun 2021.

MACHADO, M. F. R. C.; URBANETZ, S. T. Mestrado profissional em educação profissional e tecnológica no Instituto Federal do Paraná: desafios e expectativas. Atos de Pesquisa em Educação, v. 14, n. 2, p. 885-903, 2019.

MAIA, R. T. A importância da disciplina de metodologia científica no desenvolvimento de produções acadêmicas de qualidade no nível superior. Revista Urutágua, v. 14, n. 1, 2008.

PEREIRA, T. Z. M.; SILVEIRA, C. A Produção Acadêmica Da Região Norte: Uma Análise Na Ata Do Xi Encontro Nacional De Pesquisa Em Educação Em Ciências. REAMEC - Rede Amazônica de Educação em Ciências e Matemática, v. 7, n. 2, p. 245-260, 2019.

PLAYCONSOLE. Google Play Console Painel - EFE EduFIsEPT. 2021. Disponível em:

https://play.google.com/console/u/0/developers/4760644030222400117/app/497210 7118591571772/app-dashboard?timespan=thirtyDays\&showKpiMenu=null >. Acesso em: 14 Jun 2021. 
RMNC. Revista Multidisciplinar Nucleo do Conhecimento. São Paulo SP, 2021. Disponível em: < https://www.nucleodoconhecimento.com.br/ >. Acesso em: 14 Jun 2021.

ROSSI, A. V. Sobre A Valorização Das Contribuições Da Divulgação Científica No Brasil. In: VOIGT, C. L. (Ed.). O ensino de química. Ponta Grossa PR: Atena Editora, v.1, 2019. cap. 11, p.136-148.

RSD. Research, Society and Development. Vargem Grande paulista SP, 2021. Disponível em:<https://rsdjournal.org/index.php/rsd >. Acesso em: 14 Jun 2021.

SIDONE, O. J. G.; HADDAD, E. A.; MENA-CHALCO, J. P. A ciência nas regiões brasileiras: evolução da produção e das redes de colaboração científica. Transinformação, v. 28, n. 1, p. 15-32, 2016.

URBANETZ, S. T.; CASSIANO, E. L.; BETTONI, V. O Mestrado Profissional Em Educação Profissional E Tecnológica-Profept-E O Significado Dessa Oferta De Formação Em Pós Graduação No Brasil. Movimento-revista de educação, v. 7, n. 14, 2020.

VIANA, V. N.; DIAS, C. A. G. D. M. Educação Física e EPT - Temáticas em Educação Profissional e Tecnológica (EPT). Macapá AP: 2020. 45 p. ISBN 97865-86069-90-7. Disponível em:

https://www.nucleodoconhecimento.com.br/livros/wp-content/uploads/2020/09/livroeducacao-Fisica-e-EPT-educacao-profissional-e-tecnologica-2020.pdf >.

\section{Physical Education and PTE - Topics in Professional and Technological} Education (PTE). Macapá AP: 2020b. 45 p. ISBN 978-65-86069-89-1. Disponível em: $\quad<$ https://www.nucleodoconhecimento.com.br/livros/en/education/physicaleducation-and-pte $>$. 
VIANA, V. N. et al. Quadras de esportes em condições de uso adequado no Brasil: influência no ensino-aprendizagem nas aulas de Educação Física (2015). Research, Society and Development, v. 9, n. 8, p. e239985704, 2020. Disponível em: < https://rsdjournal.org/index.php/rsd/article/view/5704/4727 >.

VIANA, V. N. et al. Manuel de pratiques en éducation physique en éducation professionnelle et technologique utilisant l'application gratuite EFE - EPTFIS. Revista Científica Multidisciplinar Núcleo do Conhecimento, v. 5, p. 4, 2021d. Disponível em: < https://www.nucleodoconhecimento.com.br/education-physics-fr/manuel-depratiques $>$.

- Manuale di pratiche in educazione fisica nell'educazione professionale e tecnologica utilizzando l'applicazione gratuita EFE - EPTFIS. Revista Científica Multidisciplinar Núcleo do Conhecimento, v. 5, n. 4, p. 65-76, 2021e. Disponível em: < https://www.nucleodoconhecimento.com.br/educazione-fisica-it/manuale-dipratiche $>$.

Handbuch der Praktiken im Sportunterricht im beruflichen und technologischen Unterricht mit der kostenlosen Anwendung EFE - EPTFIS. Revista Científica Multidisciplinar Núcleo do Conhecimento, v. 5, n. 4, p. 6576, 2021f. Disponível em: < https://www.nucleodoconhecimento.com.br/bildungphysik-de/handbuch-der-praktiken $>$.

. Пособие по практике физического воспитания в профессиональном и технологическом образовании с использованием бесплатного приложения EFE EPTFIS. Revista Científica Multidisciplinar Núcleo do Conhecimento, v. 5, n. 4, p. 65-76, 2021g.

Disponível em:

https://www.nucleodoconhecimento.com.br/образование-физика-ru/пособие-попрактике >.

VIANA, V. N. et al. Manual De Praticas Em Educação Física Na Educação Profissional E Tecnológica Utilizando O Aplicativo Gratuito EFE - EPTFIS. Revista Científica Multidisciplinar Núcleo do Conhecimento, v. 5, n. 4, p. 65-76, 2021. Disponível 
em: < https://www.nucleodoconhecimento.com.br/educacao-fisica/manual-depraticas $>$.

. Manual Of Practices In Physical Education In Professional And Technological Education Using The Free Application EFE - EPTFIS. Revista Científica Multidisciplinar Núcleo do Conhecimento, v. 5, n. 4, p. 65-76, 2021b. Disponível em: < https://www.nucleodoconhecimento.com.br/education-physics-en/manual-ofpractices $>$.

- Manual De Prácticas En Educación Física En Educación Profesional Y Tecnológica Utilizando La Aplicación Gratuita EFE - EPTFIS. Revista Científica Multidisciplinar Núcleo do Conhecimento, v. 5, n. 4, p. 65-76, 2021c. Disponível em: < https://www.nucleodoconhecimento.com.br/educacion-fisica-es/manual-depracticas $>$.

YAMAGUCHI, K. K. D. L.; FURTADO, M. A. S. A Escrita Científica Como Aprendizagem Contextualizada: Uma Abordagem Metodológica A Partir De Um Experimento De Mistura De Cores In: VOIGT, C. L. (Ed.). O ensino de química. Ponta Grossa PR: Atena Editora, v.1, 2019. cap. 12, p.149-158.

Представлено: Июнь 2021.

Утверждено: Июнь 2021. 